\title{
Analisis dan Identifikasi Sisa Material Konstruksi pada Pekerjaan Beton (Studi Kasus pada pekerjaan Pembangunan Pasar Rakyat Talang Banjar)
}

\author{
Elvira Handayani ${ }^{1}$, Fenel Veronata ${ }^{2}$ \\ 'Dosen Program Studi Teknik Sipil, Fakultas Teknik, Universitas Batanghari Jambi \\ ${ }^{2}$ MahasiswaProgram Studi Teknik Sipil, Fakultas Teknik, Universitas Batanghari Jambi
}

\begin{abstract}
In the implementation of a building construction project, it cannot be avoided the emergence of the remaining construction material or called construction waste. The rest of the material is something that is of the nature more than what is required either in the form of work or construction material that is left / scattered / damaged so that it cannot be used again according to its function. The amount of residual material can be minimized by exploring the factors that cause the residual material to occur and the use of a good management system. The more residual material found on the project, it can be interpreted that the smaller the profit from implementing the project.
\end{abstract}

Keyword: analysis, identification, construction material, concrete

\section{PENDAHULUAN}

Konstruksi dan kemampuan untuk membangun sesuatu adalah salah satu keterampilan dari manusia. Pada zaman prasejarah, keterampilan membangunlah yang membedakan. Manusia berjuang untuk hidup dan berlin dung dari lingkungan yang membahayakan dengan membangun tempat tinggal dari berbagai material yang ada (Ir. Irika Widiasanti, M.T dan Lenggogeni, M.T, 2013).

Semakin berkembangnya pertumbuhan di Indonesia baik dalam hal penduduk, perekonomian maka hal tersebut mendorong semakin besarnya permintaan akan pembangunan berbagai fasilitas umum baik di sektor pemerintah maupun swasta seperti: pembangunan gedung perkantoran, perumahan, hotel, jalan raya, bandara, pelabuhan, bendungan, dan lainnya. Dengan semakin meningkatnya pembangunan di sektor konstruksi maka semakin banyak peluang terjadinya material sisa. Sedangkan material sisa dari proyek konstruksi memiliki konstribusi yang cukup besar.

Material sisa dapat diminimalisir jumlahnya dengan mendalami faktor- faktor penyebab terjadinya material sisa tersebut dan penggunan sistem manajemen yang baik. Semakin banyak material sisa yang ditemukan di proyek maka dapat diartikan bahwa semakin kecil keuntungan dari pelaksanaan proyek tersebut.

\section{Kajian Pustaka}

Kegiatan Proyek dapat diartikan sebagai salah satu kegiatan sementara yang berlangsung dalam jangka waktu terbatas, dengan alokasi sumber daya tertentu dan dimaksudkan untuk melaksanakan tugas yang sasaran nya telah digariskan dengan jelas. Disamping proyek, dikenal pula program yang mempunyai sifat sama dengan proyek. Perbedaan terletak pada kurun waktu pelaksanaan dan besarnya sumber dana yang diperlukan. Program memiliki skala lebih besar dari pada proek. Umumnya, program dapat dipecahi menjadi lebih dari satu proyek, atau suatu program merupakan kumpulan dari bermacam-macam proyek. (Ir. Iman Soeharto, 1995).

\section{Material Konstruksi}

Material Konstruksi yaitu meliputi seluruh bahan yang dibutuhkan untuk menyelesaikan bagian pekerjaan dalam satu kesatuan pekerjaan pada suatu proses konstruksi.

Material konstruksi dalam sebuah proyek terdiri dari 2 jenis adalah sebagai berikut (Universitas Brawijaya Malang Jurnal Rekayasa Sipil / Volume 4, No.3 - 2010) :

1. Bahan Permanen adalah bahan yang dibutuhkan oleh kontraktor untuk membentuk gedung, bersifat tetap sebagai elemen gedung. Jenis bahannya tercantum dalam dokumen kontrak (gambar kerja dan spesifikasi).

2. Bahan Sementara, dibutuhkan dalam membangun proyek, tetapi tidak menjadi bagian dari bangunan. Jenis bahan ini tidak dicantumkan dalam dokumen kontrak, sehingga kontraktor bebas menentukan bahan dan pemasoknya. Untuk jenis bahan ini kontraktor tidak mendapat bayaran sehingga biaya dimasukan kedalam biaya pelaksanaan pekerjaan dalam kontrak.

Material Konstruksi yaitu meliputi seluruh bahan yang dibutuhkan untuk menyelesaikan bagian pekerjaan dalam satu kesatuan pekerjaan pada suatu proses konstruksi. Material yang digunakan dalam Konstruksi dapat digolongkan dalam dua bagian besar.

1. Consumable material, merupakan material yang pada akhirnya akan menjadi bagian dari struktur fisik bangunan, misalnya:semen, pasir, kerikil, batu bata, besi tulangan, baja, dan lain-lain.

2. Non-consumable material, merupakan material penunjang dalam proses konstruksi, dan bukan merupakan bagian fisik bangunan setelah bangunan selesai, misalnya: perancah, bekisting.

\section{Beton}

Beton merupakan fungsi dari bahan penyusunnya yang terdiri dari beberapa bahan yaitu semen, agregat kasar, agregat halus dan air. (Ir. Tri Mulyono, MT, 2004).

\section{Kelebihan dan kekurangan beton}

Dalam keadaan yang mengeras, beton bagaikan batu karang dengan kekuatan tinggi. Dalam keadaan segar, beton dapat diberi bermacam bentuk, sehingga dapat digunakan untuk membentuk seni arsitektur atau 
semata-mata untuk dekoratif. (Ir. Tri Mulyono, MT, 2004). Secara umum Kelebihan dan kekurangan beton adalah :

\section{Kelebihan}
a. Dapat dengan mudah dibentuk sesuai dengan kebutuhan konstruksi
b. Mampu memikul beban yang berat
c. Tahan terhadap temperatur yang tinggi
d. Biaya pemeliharaan yang kecil

\section{Kekurangan}

1. Bentuk yang telah dibuat sulit diubah

2. Pelaksanaan pekerjaan membutuhkan ketelitian yang tinggi

3. Berat

4. Daya pantul suara yang besar

Sebagian besar bahan pembuat beton adalah bahan lokal (kecuali semen portland), sehingga sangat menguntungkan secara ekonomi, namun pembuatan beton akan menjadi mahal jika perencana tidak memahami karakteristik bahan-bahan penyusun beton yang harus disesuaikan dengan perilaku struktur yang akan dibuat.

\section{Biaya Material}

Anggaran pengeluaran untuk pelaksanaan proyek dapat dibagi menjadi enam bagian, yaitu material, tenaga kerja, peralatan, subcontracts, overhead dan keuntungan atau risiko. Perencanaan teknis mempunyai pengaruh yang sangat besar terhadap pembiayaan bagian-bagian tersebut. Jika perencanaan atau penetapan material yang mana memerlukan transportasi yang jauh, menetapkan material terlalu banyak, atau tidak diperbolehkan penggatian material dengan kualitas yang sama, maka pembiayaan akan meningkat dari yang direncanakan (Universitas Brawijaya Malang Jurnal Rekayasa Sipil / Volume 4, No.3 - 2010).

Salah satu elemen utama dari biaya proyek adalah biaya material. Beberapa penelitian menunjukan bahwa biaya material meliputi $50-70 \%$ dari biaya proyek. Biaya ini belum termasuk beberapa biaya yang biasanya tidak dihitung padahal ada (misalnya biaya penyimpanan material). Selain harga jual owner juga menanggung biaya pengadaan, seperti biaya pengiriman, penyimpanan, pemakaian dan pembuangan (untuk yang tidak digunakan).

\section{Rumus Perhitungan Sisa Material}

Material sisa dapat diminimalisir jumlahnya dengan mendalami faktor- faktor penyebab terjadinya material sisa tersebut dan penggunan sistem manajemen yang baik. Sisa material adalah kelebihan kuantitas material yang digunakan yang tidak menambah nilai suatu pekerjaan :

1. Menghitung Kebutuhan Material Kebutuhan material $=\sum$ Kebutuhan Material

2. Menghitung sisa material

Sisa material $=$ Pembelian material - Kebutuhan material

3. Menghitung biaya sisa material

Biaya sisa material $=$ Sisa material $\mathrm{x}$ Harga satuan material

4. Menghitung persentase biaya sisa material
Persentase biaya sisa material $=\frac{\text { Biaya Sisa Material }}{\text { Total Biaya Material }}$ $x 100 \%$

5. Menghitung persentase biaya sisa material terhadap total biaya proyek

Persentase total $=\frac{\text { Total Biaya Sisa Material }}{\text { Total Biaya Proyek }} \times 100 \%$

6. Menghitung persentase biaya sisa material terhadap keuntungan kontraktor.

Persentase total $=\frac{\text { Total Biaya Sisa Material }}{\text { Keuntungan Kontraktor }} \times 100 \%$

\section{Fishbone Diagram}

Diagram"Tulang Ikan"atau Fishbone diagram sering pula disebut Ishikawa diagram sehubungan dengan perangkat diagram sebab akibat ini pertama kali diperkenalkan oleh Prof. Kaoru Ishikawa dari Jepang, mengungkapkan bahwa" Diagram sebab akibat ini merupakan pendekatan terstruktur yang memungkinkan dilakukan suatu analisis lebih terperinci dalam menemukan penyebab-penyebab suatu masalah, ketidaksesuaian, dan kesenjangan yang ada.

Langkah-langkah penggunaan diagram Fishbone :

1. Dapatkan kesepakatan tentang masalah yang terjadi dan diungkapkan masalah itu sebagai suatu pertanyaan masalah.

2. Gambarkan diagram dengan pertanyaan masalah ditempatkan pada sisi kanan (membentuk kepala ikan) dan kategori utama seperti: Desain, pengadaan, penangganan, pelaksanaan, dan residual ditempatkan pada cabang-cabang utama (membentuk tulang-tulang besar dari ikan). Kategori utama ini bisa diubah sesuai dengan kebutuhan.

3. Tetapkan setiap penyebab dalam kategori utama yang sesuai dengan menempatkan pada cabang yang sesusai.

4. Untuk setiap penyebab yang mungkin, tanyakan" mengapa?" untuk menemukan akar penyebab, kemu daftarkan akar akar penyebab masalah itu pada cabang- cabang yang sesuai dengan kategori utama (membentuk tulang tulang kecil dari ikan). Untuk menemukan akar penyebab, kita dapat menggunakan teknik bertanya mengapa.

5. Interpretasikan diagram sebab akibat itu dengan melihat penyebab-penyebab yang muncul secara berulang, dapatkan kesepakatan melalui tentang penyebab itu.

\section{METODE PENELITIAN \\ Objek Penelitian dan Lokasi}

Objek penelitian dikhususkan pada proyek pembangunan pasar rakyat Talang Banjar dengan luas bangunan $\pm 1.664 \mathrm{~m} 2$ yang dibangun di jln. Orang Kayo Pingai, Milik Pemerintah Kota Jambi.

\section{Teknik Pengumpulan Data}

Penelitian pasti membutuhkan teknik dalam pengumpulan data sebagai bahan penelitian. Teknik pengumpulan data pada penelitian ini diantaranya :

\section{Data Primer}

Data primer dalam penelitian ini berupa hasil wawancara langsung dengan pelaku dilapangan seperti pelaksana lapangan dan mandor. Hasil wawancara 
berupa sisa material. Pengamatan dan pengukuran langsung dilapangan menghasilkan jumlah kebutuhan material konstruksi yang dihasilkan.

\section{Data Sekunder}

Data sekunder yang diperoleh dari pekerjaan berupa Data lainnya berupa :

1. Nota Pengeluaran

Nota pengeluaran material digunakan sebagai data menghitung sisa material.

2. Gambar Rencana

Gambar rencana diambil dari proyek konstruksi pembangunan pasar rakyat Talang Banjar kota Jambi yang akan dibangun. Gambar rencana diperlukan guna mengetahui jenis dan volume tiap-tiap pekerjaan.

\section{HASIL DAN PEMBAHASAN \\ HASIL DAN PEMBAHASAN}

Tabel 1, Rekapitulasi material yang dibutuhkan

\begin{tabular}{cccc}
\hline Jenis Material & Jumlah Material & Jumlah Material dibulatkan & Satuan \\
\hline Semen & $4.940,97$ & $4.941,00$ & sak \\
Pasir & 655,25 & 655,00 & $\mathrm{~m}^{3}$ \\
Kerikil & 364,61 & 365,00 & $\mathrm{~m}^{3}$ \\
\hline
\end{tabular}

Sumber : Data Olahan, 2018

\section{Perhitungan Sisa Material}

Tabel 2. Sisa Material

\begin{tabular}{lcccc}
\hline \multicolumn{1}{c}{ Jenis Material } & Pembelian Material & Kebutuhan Material & Sisa Material & Satuan \\
\hline Semen & $4.965,00$ & $4.941,00$ & 24,00 & Sak \\
Pasir & 660,00 & 655,00 & 5,00 & $\mathrm{~m}^{3}$ \\
Kerikil & 370,00 & 365,00 & 5,00 & $5,00 \mathrm{~m}^{3}$ \\
\hline
\end{tabular}

Sumber : Data Olahan, 2018

Catatan :

a) Volume pembelian material didapat dari nota pembelian material / barang (terlampir). b) Nilai kebutuhan material didapat dari hasil analisa perhitungan material.

\section{Perhitungan Biaya Sisa Material}

Tabel 3. Biaya sisa material

\begin{tabular}{|c|c|c|c|}
\hline Jenis Material & Sisa Material & Harga Satuan (Rp) & Harga Biaya Sisa Material \\
\hline Semen & 24,00 Sak & Rp.63.000,00 & Rp.1.512.307,15 \\
\hline Pasir & $5,00 \mathrm{~m}^{3}$ & Rp.70.000,00 & Rp.350.273,65 \\
\hline Kerikil & $5,00 \mathrm{~m}^{3}$ & Rp. $300.000,00$ & Rp. $1.500 .036,07$ \\
\hline & & TOTAL & Rp. 3.362.617 \\
\hline
\end{tabular}

Sumber : Data Olahan, 2018

Catatan :

a) Sisa material didapat dari hasil perhitungan sisa material sebelumnya.

\section{Perhitungan Persentase Biaya Sisa Material}

Tabel 4. Persentase biaya sisa material

\begin{tabular}{lcccc}
\hline \multicolumn{1}{c}{ Jenis Material } & Sisa Material & Harga Satuan (Rp) & Harga Biaya Sisa Material & Persentase \% \\
\hline Semen & $24,00 \mathrm{Sak}$ & Rp.63.000,00 & Rp. $1.512 .307,15$ & 0,101 \\
Pasir & $5,00 \mathrm{~m}^{3}$ & Rp. $70.000,00$ & Rp.350.273,65 & 0,023 \\
Kerikil & $5,00 \mathrm{~m}^{3}$ & Rp.300.000,00 & Rp. 1.500.036,07 & 0,100 \\
& & & Rp. 3.362.617 & \\
\hline
\end{tabular}

Sumber : Data Olahan, 2018

b) Harga satuan didapat dari nota Pembelian material

Perhitungan Persentase Biaya Sisa Material Terhadap Biaya Proyek

Tabel 5. Persentase Biaya Sisa Material Terhadap Biaya Proyek

\begin{tabular}{ccccc}
\hline No & Material & Total Biaya Sisa Material & Total biaya Proyek & Persentase \% \\
\hline 1. & Material & Rp. 3.362.617 & Rp.6.625.000.000 & $0,0507 \%$ \\
& & Jumlah & $0,0507 \%$ \\
\hline
\end{tabular}

Sumber : Data Olahan, 2018

Catatan :

a) Biaya proyek di dapat dari kontrak kerja PT. Belimbing Sriwijaya.

\section{SIMPULAN}

Penyebab terjadinya sisa-sisa material pada pekerjaan pembangunan Pasar Rakyat Talang Banjar dapat dilihat di bawah : 


\section{Desain}

a) Perubahan desain (terjadi akibat ketidaksesuaian gambar rencana dan lapangan)

b) Informasi gambar yang kurang (detail-detail gambar rencana yang kurang lengkap)

\section{Pengadaan}

a) Kesalahan Pemesanan, kelebihan, kekurangan, dll (pada saat pemesanan tidak dihitung terlebih dahulu material yang dibutuhkan)

b) Pesanan tidak dapat dilakukan dalam jumlah kecil

\section{Penanganan}

a) Membuang atau melempar material (pada saat pembongkaran material ada yang melempar atau membuang material menyebabkan terjadinya material rusak)

b) Penyimpanan material yang tidak benar menyebabkan

\section{Lain-Lain}

a) Buruknya pengontrolan material diproyek dan perencanaan manajemen terhadap sisa material (kurangnya koordinasi antar pekerja dalam proyek tersebut menyebabkan material diproyek terjadi sisa

b) Adapun Perhitungan Sisa Material dan biaya sisa material pada pekerjaan pembangunan Pasar Rakyat Talang Banjar antara lain

\begin{tabular}{lcccc}
\hline \multicolumn{1}{c}{ Jenis Material } & Sisa Material & Harga Satuan $(\mathrm{Rp})$ & Harga Biaya Sisa Material & Persentase \% \\
\hline Semen & $24,00 \mathrm{Sak}$ & Rp.63.000,00 & Rp. $1.512 .307,15$ & 0,101 \\
Pasir & $5,00 \mathrm{~m}^{3}$ & $R p .70 .000,00$ & Rp.350.273,65 & 0,023 \\
Kerikil & $5,00 \mathrm{~m}^{3}$ & Rp.300.000,00 & Rp. $1.500 .036,07$ & 0,100 \\
& & & Rp. 3.362.617 & \\
\hline
\end{tabular}

c) Perhitungan Persentase Biaya Sisa Material Terhadap Biaya Proyek

\begin{tabular}{|c|c|c|c|c|}
\hline No & Material & Total Biaya Sisa Material & Total biaya Proyek & Persentase \% \\
\hline 1. & Material & Rp. 3.362 .617 & $\begin{array}{l}\text { Rp.6.625.000.000 } \\
\text { Jumlah }\end{array}$ & $\begin{array}{l}0,0507 \% \\
0,0507 \%\end{array}$ \\
\hline
\end{tabular}

Sumber : Data Olahan, 2018

\section{DAFTAR PUSTAKA}

Asiyanto (2003), Construction Project Cost Management, PT Pradnya Paramita Jakarta

Dipohusodo, istimawan (1996), manajemen proyek dan konstruksi, jilid 1, penerbit kanisius Yogyakarta

Djojowirono, Soegeng, Ir. (2005), Manajemen Konstruksi, Biro Penerbit TS. UGM: Yogyakarta. Tim

Manajemen Konstruksi, Vil Press, 2

Wulfram I. Ervianto. (2005), Manajemen Proyek Konstruksi, ANDI, Yogyakarta.

Soeharto, Imam, 1995,1997, Manajemen Proyek Dari Konseptual Sampai Operasional, Erlangga: Jakarta

Tim Manajemen Konstruksi, UII Press, 2001

Husen, Akbar, Ir. MT. (2011), Manajemen Proyek, ANDI, Yogyakarta.

Djojowirono, Soegeng, Ir. (2005), Manajemen onstruksi, Biro Penerbit TS. UGM: Yogyakarta. 